\title{
Toxic Effect of Antibiotics on Freshwater Algal Systems and the Mechanisms of Toxicity: A Review
}

\author{
Barsha Roy and P. K. Suresh $\dagger$
}

School of Biosciences and Technology, VIT, Vellore-632 014, India

†Corresponding author: P. K. Suresh; p.k.suresh@vit.ac.in

Nat. Env. \& Poll. Tech.

Website: www.neptjournal.com

Received: 20-01-2021

Revised: 18-02-2021

Accepted: 24-02-2021

\section{Key Words:}

Antibiotics

Non-target organisms

Green algae

Toxicity

Mode-of-action

\section{ABSTRACT}

Antibiotics are used to treat bacterial infections in humans and animals and also act as a growth promoter for poultry. Due to incomplete metabolism, these antibiotics are excreted in the environment in their parental forms and accumulates in the aquatic ecosystem. Besides the evolution of antibioticresistant bacteria, these drugs can damage non-target organisms. Green algae are highly sensitive to different antibiotics. Damage in the algal population will cause imbalances in the ecosystems. Till now, the mechanisms of antibiotic toxicity towards algae have not been completely elucidated. It was observed that antibiotics mainly affected the photosynthetic machinery and decreased the carbon fixation process, finally resulting in algal growth inhibition. This present review deals with antibiotics classification, various routes of antibiotics exposure to the freshwater environment, sensitivity towards the different classes of antibiotics, possible Mode-of-Action (MOA) on algal systems, and gaps that need to be filled. Significant gaps include the unavailability of proper eco-toxicological data for antibiotics. Moreover, they exist in nature as complex mixtures, and their behavior in the ecosystem may vastly differ from the parent molecules. To improve our understanding of antibiotic responses mechanism in real-life scenarios, mixture toxicity studies may be the first step.

\section{INTRODUCTION}

After the discovery of penicillin in 1929, antibiotics are widely used to treat different bacterial infections in humans and animals. They are also used for aquaculture and livestock development (Liang et al. 2013). From the years 2000 to 2010, the use of antibiotics has increased significantly throughout the world where India became a major contributor. Seasonal variations in terms of the usage of antibiotics were observed (Van Boeckel et al. 2014). By the year 2030 antibiotic consumption will increase by approximately $67 \%$ (Van Boeckel et al. 2015).

India has produced a considerable amount of antibiotics in the past. Ninety percent $(90 \%)$ of the antibiotics, used in humans and other farm animals, are excreted in their unaltered forms through urine and feces. In India, the purchase rate of antibiotics, without an authorized prescription, is high. Hence, the residues are also proportionally higher than those areas where usage is based on doctor's prescription (Mutiyar \& Mittal 2014). From 2000 to 2010, it has been reported that the use of antibiotics has increased by $36 \%$ with $75 \%$ of the increases attributable to be due to indiscriminate use and release of antibiotics by the citizens of Brazil, Russia, India, China, and South Africa (BRICS) (Laxminarayan et al. 2016). For this reason, countries like India facing an increasing threat of infectious diseases spiraling out of control (Laxminarayan et al. 2013, 2016).

In 2017, antibiotics were mostly used in India to treat pneumonia or lower respiratory tract infection; followed by the treatment of skin and soft tissues; central nervous system infection; bronchitis, and infection of the cardiovascular system. Besides these, antibiotics have also been used to treat intra-abdominal sepsis, upper respiratory tract, bone/ joint, and gynecological infections. For medical prophylaxis, mostly the antibiotics ceftriaxone, piperacillin-tazobactam, and meropenem are prescribed. In contrast, for surgical prophylaxis, antibiotics prescribed frequently are cefuroxime, amikacin, and ceftriaxone (Singh et al. 2019). Prolonged use of antibiotics after the operation could increase the formation of antibiotic resistance genes (Hagel \& Scheuerlein 2014).

This widespread use of antibiotics contributed to the genesis of antibiotic-resistant bacteria, with significant detrimental impacts on human health (Smith et al. 2013). Due to the increased and indiscriminate usage of antibiotics, significant amounts of them are discharged into the aquatic environments from diverse sources, such as during the process of manufacturing, human or animal excreta, and emission from the Wastewater Treatment Plants (WWTPs) (Deng et al. 2016, Wu et al. 2016b, Yan et al. 2013). Some of the primary sources, including hospitals, poultry farms, 
farmlands, and aquacultures (Fairbairn et al. 2016, NogueraOviedo \& Aga 2016, Pal et al. 2014), and some of the uncontrolled sources like septic tanks, leaking sewage lines, landfills, and inaccurately disposed-off waste (GonzálezPleiter et al. 2019) are responsible for antibiotic disposal into the freshwater system. Antibiotics from these sources are major determinants for the acquisition of antibiotic resistance genes that may cause permanent damage to the genetic pool of the exposed ecosystem (Yang et al. 2014). The harmful impact on the micro-organisms can occur even at low concentrations (ng or $\mu \mathrm{g} \mathrm{L}^{-1}$ ) (Liu et al. 2017).

Antibiotics can be classified into 11 major classes based on their MOA towards the bacteria (González-Pleiter et al. 2019). Commonly found antibiotics in an aquatic ecosystem are tetracyclines (TCs), sulphonamides (SAs), macrolides (MLs), and quinolones (QNs). In an aqueous environment, antibiotics caused toxicity and the formation of antibiotic resistance genes in aquatic micro-organisms (Dong et al. 2016). The other primary concern is the toxicity of antibiotics on other aquatic organisms, which are not their direct targets. Previous studies have shown that antibiotics caused acute and chronic toxicity to the different aquatic species, including algae, crustaceans, and fishes (Huang et al. 2014, Seoane et al. 2014, Wang et al. 2016). In aquatic environments, climatic condition can alter their chemical structures. They can also be degraded by photochemical reactions, which play a major role in determining the fate of the antibiotics (Liu et al. 2017).

As organic manure, livestock waste-containing antibiotic residues have been used in farms which increased the quantity of antibiotics into the soil than pesticides. Some of these antibiotic residues can be present in their biologically active form and can cause significant harm to the environment (Xiang et al. 2016). Generally, freshwater algae showed higher sensitivity towards antibiotics than marine algae. At very low concentrations, both Ciprofloxacin (CIP) and Erythromycin (ERY) inhibited cellular growth in freshwater algae (González-Pleiter et al. 2019). Almost all the antibiotic classes (very low $\mathrm{EC}_{50}$ values) showed higher toxicity towards different algae. Some of the antibiotics can even induce intracellular Reactive Oxygen Species (ROS) inside blue-green algae (González-Pleiter et al. 2019), which are highly sensitive to antibiotics.

Unicellular green algae are the major producers of the ecosystem and form the base in the food chain. Any changes in the algal population can disrupt the ecological balance in the food chain (Mutiyar \& Mittal 2014). Algae are highly sensitive to many toxicants, including antibiotics. Laboratory-based toxicity studies can be performed easily on algae, which makes them a biomonitoring tool to evaluate the toxic potential of contaminants (Mutiyar \& Mittal 2014). Due to the bioaccumulation of different pollutants, they can also act as a biomarker (Barhoumi \& Dewez 2013).

Previous studies found the effects of antibiotics by mainly focussing on the mechanisms of evolution of antibiotic-resistant bacteria. But it was observed that antibiotics can also pose a significant threat to the non-target organisms in the ecosystem. Green algae were found to be affected dramatically by antibiotics. The present review focused on the different antibiotics and detailed the severe damages caused to the algal populations. This study also tried to find out possible mechanisms behind the toxicity of the algae caused by the antibiotics.

\section{Antibiotics of Serious Eco-Toxicological Concern Available in Freshwater Ecosystems}

Antibiotics exist as persistent pollutants both in terrestrial and aquatic ecosystems. Its bioaccumulation, in the environment, may plausibly explain its concentrations exceeding the therapeutic concentration (Brandt et al. 2015). It has become mandatory to identify the sources of the antibiotics from where they are released into the environment to control antibiotic usage and to regulate their release.

\section{ROUTES OF EXPOSURE OF ANTIBIOTICS TO THE AQUATIC ENVIRONMENT}

Initially, antibiotics were isolated from natural sources like fungus. Hence, antibiotics were present in the environment long before humans identified them to treat bacterial infections. During the twentieth century, mass production of antibiotics began, which resulted in antibiotic-mediated selection pressures in the entire bacterial population (Larsson 2014). The identification of chemical structures of antibiotics isolated from natural sources led to their mass production in the laboratory (Mazel \& Davies 1999). Their increased production leads to their higher release in the environment. The concentrations of various antibiotics in several Asian countries were found to be in the range of mg. $\mathrm{L}^{-1}$ (Gothwal $\&$ Shashidhar 2015). One primary source is sewage through which antibiotics can enter the environment. Antibiotics can be released into the soil through animal manure, or they can be applied directly to the plants to fight against plant pathogens (Shade et al. 2013). Antibiotics can be present in the aquatic environment in both their parental and metabolites forms.

Incomplete metabolism by humans or animals resulted in the release of almost $50-80 \%$ of antibiotics in their parental form. The remaining are released into the environment as metabolites through the urine and feces of the treated organisms (Manzetti \& Ghisi 2014). Because of incomplete elimination by sewage treatment plants these antibiotics 
can be discharged into the different freshwater systems (Wu et al. 2016a). Improper disposal of expired or unused antibiotics resulted in their presence in WWTPs and landfills, which further can contaminate the freshwaters (et al. 2018). Drug wastage can be reduced by prescribing a lower dose. This will eventually prevent their excessive release into the environment. Based on the present release data, public health-associated individuals can issue guidelines about the "environmentally safe dose" that can be released into the environment (Daughton \& Ruhoy 2013). Before awarding a marketing license to the antibiotics, a proper environmental risk assessment should have to perform (EMA 2006).

\section{ANTIBIOTICS OF MAJOR THREAT TOWARDS THE ENVIRONMENT}

It is important to identify the key marker antibiotics that can cause adverse effects in the environment. The identification of certain antibiotics may be due to their higher usage in humans than others, e.g., penicillin, SAs, macrolide, and quinolone. The current challenges are to estimate their nature and duration of persistence, apart from their release characteristics into the environment (Välitalo et al. 2017). Table 1 represents the different antibiotic classes with their MOA towards bacteria and the resistance mechanism in bacteria. It was observed that antibiotics CIP, norfloxacin (NOR), enrofloxacin (ENR), trimethoprim (TMP), sulfamethoxazole
(SMX), oxytetracycline (OTC), chlorotetracycline (CTC), azithromycin (AZM), and ERY were found in very high quantities in the freshwater samples taken from the environment (> $\left.1 \mu \mathrm{g} . \mathrm{L}^{-1}\right)$ (Ngumba et al. 2016, Wei et al. 2011, 2012). The persistence property and half-life of antibiotics vary significantly with temperature, $\mathrm{pH}$, and geographical locations (Andreozzi et al. 2004, Braschi et al. 2013, Mitchell et al. 2014).

\section{RATIONALE FOR MODELLING THE ECOSYSTEM RELATED TO ANTIBIOTIC DISCHARGE}

For the modeling, the crucial determinants among all the variables are biosorption potential, dilution effects, the biodegradability of the antibiotics, and photolysis. Besides these, seasonal variation also plays a role in the modeling. Chronic exposure to varying amounts of antibiotics plays a significant role in these effects. Hence, the characterization of samples from water bodies as well as the algal species present, which may be sentinels of environmental damage is necessary. In a paper, it had been demonstrated that ofloxacin, sulfamethoxazole, and sulfadiazine were the important antibiotics to be considered for risk assessment and that algae were a good model for testing toxicity (Zhang et al. 2020). In this context, complementary modeling approaches involving the Concentration Addition (CA)

Table 1: Classes of antibiotics, their examples, MOA and resistance mechanism in bacteria.

\begin{tabular}{|c|c|c|c|}
\hline Antibiotic Class & Example & MOA & Mechanism of Resistance \\
\hline$\beta$-Lactam & Penicillin $\mathrm{G}$, ampicillin, amoxicillin & $\begin{array}{l}\text { Inhibits synthesis of cell } \\
\text { wall and assembly of murein }\end{array}$ & Cell wall protein modification \\
\hline Aminoglycosides & Streptomycin, gentamicin & $\begin{array}{l}\text { Protein synthesis inhibition } \\
\text { (30S inhibitor) }\end{array}$ & $\begin{array}{l}\text { Modification of the ribosomal binding site and/ or pro- } \\
\text { ducing aminoglycoside modifying enzymes }\end{array}$ \\
\hline Macrolides & $\begin{array}{l}\text { Erythromycin, roxithromycin, clar- } \\
\text { ithromycin, tylosin, spiramycin }\end{array}$ & $\begin{array}{l}\text { Protein synthesis inhibition } \\
\text { (50S inhibitor) }\end{array}$ & Methylation of the rRNA in gram-positive bacteria \\
\hline Quinolones & $\begin{array}{l}\text { Oxolinic acid, nalidixic acid, flum- } \\
\text { equine }\end{array}$ & $\begin{array}{l}\text { Inhibits DNA replication } \\
\text { (DNA gyrase) }\end{array}$ & $\begin{array}{l}\text { Alteration of DNA gyrase and mutation of the porins of } \\
\text { the outer membrane }\end{array}$ \\
\hline Fluoroquinolones & $\begin{array}{l}\text { Ciprofloxacin, enrofloxacin, nor- } \\
\text { floxacin, ofloxacin }\end{array}$ & $\begin{array}{l}\text { Inhibits DNA replication } \\
\text { (DNA gyrase) }\end{array}$ & Same as quinolones \\
\hline Tetracyclines & $\begin{array}{l}\text { Tetracycline, oxytetracycline, min- } \\
\text { ocycline, chlorotetracycline }\end{array}$ & $\begin{array}{l}\text { Protein synthesis inhibition } \\
\text { ( } 30 \mathrm{~S} \text { inhibitor) }\end{array}$ & $\begin{array}{l}\text { Alteration in the binding site and inducing efflux in } \\
\text { E. coli }\end{array}$ \\
\hline Sulfonamides & $\begin{array}{l}\text { Sulfadiazine, sulfadimethoxine, } \\
\text { sulfamethoxazole }\end{array}$ & Inhibits folic acid synthesis & $\begin{array}{l}\text { Resistance mediated by plasmid and integron, and } \\
\text { mutation in chromosomes }\end{array}$ \\
\hline Lincosamides & Clindamycin, lincomycin & $\begin{array}{l}\text { Protein synthesis inhibition } \\
\text { (50S inhibitor) }\end{array}$ & $23 \mathrm{~S}$ subunit of rRNA gets methylate \\
\hline Rifamycins & Rifamycin & $\begin{array}{l}\text { RNA synthesis inhibition } \\
\text { (RNA polymerase) }\end{array}$ & Mutation in the $\beta$-chain of the RNA polymerase enzyme \\
\hline Chloramphenicol & Chloramphenicol & $\begin{array}{l}\text { Protein synthesis inhibition } \\
\text { (50S inhibitor) }\end{array}$ & $\begin{array}{l}\text { Antibiotic inactivation by the enzyme chloramphenicol } \\
\text { acetyltransferase }\end{array}$ \\
\hline Diaminopyrimidine & Trimethoprim, iclaprim & Inhibits folic acid synthesis & $\begin{array}{l}\text { Replacement of antibiotic target by dihydrofolate } \\
\text { reductase }\end{array}$ \\
\hline
\end{tabular}


and Independent Action (IA) models may help in the better extrapolation of laboratory-based data. Hormesis, as well as the adsorption process of cefradine and its rate, were studied in Chlamydomonas reinhardtii. Optimization of the reaction conditions (temperature, $\mathrm{pH}$, and algal cell density) was done using the Box-Benken design. The dissolved organic matter, specifically the excited triplet state, contributed by the natural biofilms (BDOM), played a significant role in the photodegradation of oxytetracycline. Since the results were at variance with that seen in the case of fulvic acid (inhibition of photodegradation), characterization of these variables in their natural habitat would improve our ability to predict the relative contributions made by individual antibiotics to overall toxicity towards the algal system (Hua et al. 2018). The triplet state, reactive extracellular organic matter (EOMs) in Chlorella vulgaris was found to account for the majority of the degradation of chlorotetracycline, by the mechanism of the electron transfer process (Tian et al. 2019).

\section{DIFFERENT ANTIBIOTICS TOXICITY ON GREEN ALGAE}

The original rationale behind the development of antibiotics was to eliminate the pathogenic forms without harming the host organism selectively. But as these environmental pollutants (both the parent and/or the altered forms) can persist longer in their active form even in very low concentrations (ng. $\mathrm{L}^{-1}-\mu \mathrm{g} . \mathrm{L}^{-1}$ ), they may pose a significant risk of bioaccumulation in the food chain (Huang et al. 2014). Therefore, toxicity testing of these antibiotics became important. For this, different methods are available for performing acute and chronic toxicity experiments in the various test organisms (Brausch et al. 2012). The most commonly used micro-organisms are cyanobacteria (Ebert et al. 2011), proteobacteria (Backhaus et al. 2000), and multiple species of green algae and microalgae (González-Pleiter et al. 2013, Magdaleno et al. 2015). Algae are one of the best organisms to test the ecotoxicity of any chemical as they are cost-effective, very much sensitive towards pollutants, easy to maintain in the laboratory, and the results obtained are reliable.

Among the algal species, Pseudokirchneriella subcapitata is used more commonly for toxicity testing (Baumann et al. 2015, Kolar et al. 2014). Except this, other different species have been also used for antibiotic toxicity testing (De Vasconcelos et al. 2017, Ebert et al. 2011, Seoane et al. 2014, Wang et al. 2019). Previously, the median effective concentration $\left(\mathrm{EC}_{50}\right)$ or median lethal concentration $\left(\mathrm{LC}_{50}\right)$ was used to determine the toxicity of an antibiotic on unicellular green algal species and were ranked accordingly (Sebaugh 2011). From Table 2, we can see that macrolides and OTC were most toxic with an $\mathrm{EC}_{50}$ value below $1 \mathrm{mg} . \mathrm{L}^{-1}$. The sensitivity of $C$. vulgaris was found to be less when compared with other algal species tested. Previous

Table 2: $\mathrm{EC}_{50}$ values of different antibiotics on different green algal species.

\begin{tabular}{|c|c|c|c|c|}
\hline Antibiotic Class & Antibiotic Name & Algal species & $\mathrm{EC}_{50}$ value $(\mathrm{mg} / \mathrm{L})$ & References \\
\hline \multirow[t]{2}{*}{$\beta$-Lactum } & Amoxicillin & P. subcapitata & $>2000$ & (Magdaleno et al. 2015) \\
\hline & & & $>1500$ & (González-Pleiter et al. 2013) \\
\hline \multirow[t]{4}{*}{ Macrolides } & Clarithromycin & D. subspicatus & 0.0371 & (Baumann et al. 2015) \\
\hline & & P. subcapitata & 0.23 & (Villain et al. 2016) \\
\hline & Erythromycin & P. subcapitata & 0.35 & (González-Pleiter et al. 2013) \\
\hline & & & 0.038 & (Machado and Soares 2018) \\
\hline \multirow[t]{11}{*}{ Quinolones } & Enrofloxacin & D. subspicatus & 5.57 & (Ebert et al. 2011) \\
\hline & & P. subcapitata & 18.7 & (Robinson et al. 2005) \\
\hline & Ciprofloxacin & D. subspicatus & $>8$ & (Ebert et al. 2011) \\
\hline & & P. subcapitata & 113 & (Magdaleno et al. 2015) \\
\hline & & & 39 & (Martins et al. 2012) \\
\hline & & & 187 & (Robinson et al. 2005) \\
\hline & Ofloxacin & P. subcapitata & 12.1 & (Robinson et al. 2005) \\
\hline & & & 1.44 & (Isidori et al. 2005) \\
\hline & Norfloxacin & C. vulgaris & 10.4 & (Eguchi et al. 2004) \\
\hline & & P. subcapitata & $>80$ & (González-Pleiter et al. 2013) \\
\hline & & & 16.6 & (Eguchi et al. 2004) \\
\hline \multirow[t]{3}{*}{ Tetracyclines } & Tetracycline & P. subcapitata & 3.31 & (González-Pleiter et al. 2013) \\
\hline & Oxytetracycline & C. vulgaris & 3.58 & (Siedlewicz et al. 2020) \\
\hline & & P. subcapitata & 1.04 & (Kolar et al. 2014) \\
\hline Sulfonamides & Sulfamethoxazole & Green algae & 1.53 & (Johnson et al. 2015) \\
\hline \multirow[t]{2}{*}{ Diaminopyrimidine } & Trimethoprim & P. subcapitata & 129 & (Kolar et al. 2014) \\
\hline & & & 83.8 & (De Liguoro et al. 2012) \\
\hline
\end{tabular}


studies have shown that $\mathrm{EC}_{50}$ values will be in the range of $\mu \mathrm{g} . \mathrm{L}^{-1}$ to $\mathrm{mg} . \mathrm{L}^{-1}$ (Yang et al. 2008). Earlier experiments proved that sulphonamides (Białk-Bielińska et al. 2011), tetracyclines (Yang et al. 2013), and macrolides (Baumann et al. 2015) had severe effects on algal growth and development in terms of growth inhibition. Sometimes, antibiotics showed hormesis, i.e., the same antibiotics when used in lower doses can stimulate algal growth, but if applied in higher concentrations, showed growth inhibition effects (Baumann et al. 2015, González-Pleiter et al. 2013). Algae can induce defense mechanisms against oxidative stress caused by antibiotics. Increasing concentrations of Norfloxacin affect the activity of two antioxidative enzymes viz. catalase (CAT) and glutathione S-transferase (GST). Similarly, OTC can change the activity of CAT and peroxidase enzymes (Vilvert et al. 2017).

In reality, antibiotics are found as a mixture with other antibiotics or some other contaminants such as heavy metals, nanoparticles, or the metabolites of antibiotics themselves. So it is necessary to identify the relative contributions made by the antibiotic to the toxicity towards algae in complex mixtures. A variety of antibiotics like tylosin and macrolides or other antibiotics with sulfonamides showed simple additive effects. Synergistic effects could be seen in the binary mixture of the same classes of antibiotics like sulfonamides and trimethoprim. A combination of tetracycline with the 7-aminocephalosporanic acid showed antagonistic effects (Gao et al. 2013, Liu et al. 2018). Previous studies also showed that working on the antibiotic mixture was more important than the individual molecules. One of the early studies evaluated the toxicity of antibiotic combinations of ERY and ENR to $C$. vulgaris where the mixture showed synergism. This result could be correlated with an increase in antioxidant enzymes as well as in MDA and glutathione content (Wang et al. 2019). In another study, 16 chemicals with different MOA were tested in algal systems. These concentration-response analyses were performed for 16 different biocides and mixtures with all 16 substances. It was found that the IA model was better than the CA in predicting the toxicity of algal systems. The alternative hypothesis of CA resulted in an overestimation of mixture toxicity, but differences between observed and predicted effect concentrations did not exceed a factor of 3.2 (Faust et al. 2003).

\section{MODELLING APPROACHES TO DETERMINE THE TOXICITY OF MIXTURES}

Generally, concentration addition (CA) and independent action (IA) are the two models used to determine the combined effects of the mixture of different chemicals. CA model is used when the components in the mixture display a similar kind of MOA; whereas, the IA model is applicable where the MOA is different for the components present in the mixture (Nweke et al. 2015). CA model can be depicted as follows:

$$
I C_{x(\text { mix })}=\left(\sum_{i=1}^{n} \frac{\pi_{i}}{I C_{x i}}\right)^{-1}
$$

Where $n$ denotes the total number of components, $\pi_{i}$ represents the proportion of $i^{\text {th }}$ component in the mixture so that summation of $\pi_{i}$ should be equals to $1, I C_{x i}$ is the concentration of the $i^{\text {th }}$ component which give the effect $x$ when acted individually.

IA model can be mathematically expressed as:

$$
E\left(C_{\text {mix }}\right)=1-\prod_{i=1}^{n}\left[1-E\left(C_{i}\right)\right]
$$

Where $E\left(C_{m i x}\right)$ is the total effect caused by the mixture containing $n$ number of components, $C_{i}$ denotes the concentration of the $i^{\text {th }}$ compound, and $E\left(C_{i}\right)$ is the effect caused by the component individually.

After determining the effects of individual components, the effect of the mixture can be predicted by applying these $\mathrm{CA}$ and IA models. Then the predicted value is compared with the obtained value. The ratio between the observed and predicted value denotes the interaction present between the components of the mixture. A value less than 1 denotes antagonism between the components; whereas a value greater than 1 shows synergism. If the value equals 1 then it is said that components in the mixture present additive effects $(\mathrm{Li}$ et al. 2014).

\section{PROBABLE DIFFERENTIAL ALGAL TOXICITY MECHANISM(S) OF ANTIBIOTIC TOXICITY}

As mentioned in the earlier sections, it was observed that some antibiotics also affected many non-target organisms like eukaryotic green algae (De Liguoro et al. 2012, de Vasconcelos et al. 2017) besides being toxic to the target organism, i.e., bacteria. However, there were no specific trends observed for algal sensitivity towards antibiotics. This observation suggests that there can be variation in species sensitivity depending on the use of antibiotics. Until now, researchers have focused on morphological changes like inhibition of cellular growth and cytotoxicity (GonzálezPleiter et al. 2013, Magdaleno et al. 2015). Photosynthesis mechanism damage by oxidative stress and the antioxidant defense mechanisms are used to determine the molecular mechanism(s) of antibiotic toxicity. An antibiotic like amoxicillin did not show any kind of toxicity towards the algal system. The cause may be due to its toxic effects on the formation of the bacterial cell wall. Hence, they do not cause any harm to algae (González-Pleiter et al. 2013). It was also found out that the eukaryotic algal photosynthetic 
mechanism was explicitly inhibited by antibiotics (Liu et al. 2011). From Table 2, it is evident that macrolide antibiotics like clarithromycin and erythromycin are highly toxic towards freshwater algal species with very low $\mathrm{EC}_{50}$ values (Baumann et al. 2015, González-Pleiter et al. 2013, Machado and Soares 2018, Minguez et al. 2016, Villain et al. 2016). In bacteria, this group of antibiotics inhibits protein synthesis by binding with the $50 \mathrm{~S}$ ribosomal subunit. The algal chloroplast contains homologs of bacterial 70S ribosomes. Maybe this is why antibiotics affect the photosynthetic machinery of eukaryotic algal species (Villain et al. 2016). It was also observed that erythromycin inhibited several photosynthetic mechanisms like carbon assimilation, electron transport, and photophosphorylation (Liu et al. 2011). It can be said that antibiotics cause toxicity to the algal species by interfering or inhibiting the pathways responsible for chloroplast metabolism, which results in the dysfunction of the photosynthetic apparatus and eventually reduces cell growth (Matsumoto et al. 2012, Wang et al. 2015). Another study found out that tetracyclines affected the mitochondrial translation process (Moullan et al. 2015). Previous studies also showed that antibiotics like roxithromycin, when exposed to the algae $C$. pyrenoidasa for 21 days (long-term exposure), increased the SOD, CAT, and MDA, which suggested that the antibiotic caused oxidative stress in the algae ( $\mathrm{Li}$ et al. 2020). It was also found out that eukaryotic algae are less sensitive towards levofloxacin (LEV) and oxytetracycline when compared with the blue-green algae (Zhou et al. 2020). Again, the effects of the same antibiotic may vary when exposed to different organisms (Han et al. 2020).

C. vulgaris exposed to environmentally relevant concentrations of sulfamethoxazole, and norfloxacin (less than ten days) showed significant cell-density inhibition ( $p$ $<0.05$ ) when compared with the control group. Antioxidant enzymes, like, SOD, CAT, and peroxidase (POD) activities also varied with respect to control, which proved that these antibiotics caused oxidative stress (Niu et al. 2019). Triclosan, one of the broad-spectrum antibiotics and can be detected in the aquatic system, was found to be highly toxic to the algae. It was also observed that the by-products of triclosan were more toxic than their parent compound (Dann \& Hontela 2011). It was noted that at high concentrations, LEV significantly inhibited the algal growth and increased oxidative stress to the system. LEV also inhibited the photosynthesis mechanism (Wan et al. 2014).

\section{REMOVAL AND/OR DEGRADATION OF ANTIBIOTICS BY ALGAL POPULATION}

It was also noted that algae played a significant role in the removal and or degradation of antibiotics. This removal mechanism might be because of the self-defense mechanism. It was found out that the half-lives of the antibiotic florfenicol were between 3.53 to 7.63 days. It was also observed that at the concentration of $46 \mathrm{mg} . \mathrm{L}^{-1}$, the removal efficiency by Chlorella $s p$. was almost $97 \%$. Further, this algal species showed nearly $74 \%$ removal despite the presence of a high concentration (159 mg. $\mathrm{L}^{-1}$ ) of the antibiotic. These results suggested that this Chlorella sp. (an alga known to have considerable bioremediation potential) has shown promise in the removal of florfenicol antibiotics as well (Song et al. 2019). In another study, scientists evaluated the bioremediation properties of four algal species. The removal of ten antibiotics (belong to three classes: sulphonamides, macrolides, and fluoroquinolones) was evaluated. This study demonstrated that variation was based on the antibiotics' dissipation potential and also on algal species variation. The study showed the degradation products of the antibiotics had lower toxicity than their parental products (Kiki et al. 2020). It is also essential to design the experiment properly to understand the contribution of different abiotic factors (Li et al. 2020).

\section{FUTURE CHALLENGES}

Most of the studies, to date, have focussed on the effects of a single antibiotic on the freshwater algal system. As mentioned earlier, antibiotics can be mostly found as a mixture of toxicants. In the mixture, they may show additive, synergistic, or antagonistic effects on the algae when compared with the individual toxicant. It is necessary to investigate the toxic effects of the mixture to get more realistic data (Roose-Amsaleg \& Laverman 2016). Though there are some studies performed to evaluate toxicities of mixtures on algal species (González-Pleiter et al. 2013, Magdaleno et al. 2015, Wang et al. 2019), mechanistic details are inadequate in the laboratory setting.

Moreover, there is a lack of adequate eco-toxicological data available for all the antibiotics, despite their presence in the environment in large amounts (e.g., azithromycin). In contrast, some antibiotics (like tetracycline and oxytetracycline) got more recognition than others. The reason behind this is not known.

\section{CONCLUSION}

From this review, it can be concluded that the ever-increasing production and excessive usage of persistent antibiotics can be classified as an emerging pollutant. Though antibiotics are specific to treat several bacterial infections, they can exhibit toxic effects on non-target organisms. Eukaryotic green algae are one of the most critical non-target organisms studied for determining antibiotic toxicity. Species sensitivity may vary 
depending on the antibiotic exposed. Until now, the mechanistic approach of evaluating the toxicity of antibiotics in algae has not been explored systematically. There are still huge gaps found in the eco-toxicological data of antibiotics, as their toxicity can be altered due to their interactions with other toxicants in the environment. Moreover, environmental factors such as humidity, temperature, $\mathrm{pH}$, as well as other variables like BDOM, can also modify the toxicity of antibiotics. Toxicity evaluation of antibiotics is expected to aid the regulators to modify existing guidelines for proper antibiotic disposal.

\section{ACKNOWLEDGEMENT}

The authors thank the management of VIT for their unstinted and constant support and for creating the scientific ambiance that made possible the compilation of this review possible.

\section{REFERENCES}

Andreozzi, R., Caprio, V., Ciniglia, C., De Champdoré, M., Lo Giudice R. and Marotta, R. 2004. Antibiotics in the environment: occurrence in Italian STPs, fate, and preliminary assessment on algal toxicity of amoxicillin. Environ. Sci. Technol., 38: 6832-6838.

Backhaus, T., Scholze, M. and Grimme, L. 2000. The single substance and mixture toxicity of quinolones to the bioluminescent bacterium Vibrio fischeri. Aquat. Toxicol., 49: 49-61.

Barhoumi, L. and Dewez, D. 2013. Toxicity of superparamagnetic iron oxide nanoparticles on green alga C. vulgaris. BioMed Res. Int., 13: 36-49.

Baumann, M., Weiss, K., Maletzki, D., Schüssler, W., Schudoma. D. and Kopf, W. 2015. Aquatic toxicity of the macrolide antibiotic clarithromycin and its metabolites. Chemosphere, 120: 192-198.

Białk-Bielińska, A., Stolte, S., Arning, J., Uebers, U., Böschen, A. and Stepnowski, P. 2011. Ecotoxicity evaluation of selected sulfonamides. Chemosphere, 85: 928-933.

Brandt, K.K., Amézquita, A., Backhaus, T., Boxall, A., Coors, A. and Heberer, T. 2015. Ecotoxicological assessment of antibiotics: a call for improved consideration of microorganisms. Environ. Int., 85: 189-205.

Braschi, I., Blasioli, S., Fellet, C., Lorenzini, R., Garelli, A. and Pori, M. 2013. Persistence and degradation of new $\beta$-lactam antibiotics in the soil and water environment. Chemosphere, 93: 152-159.

Brausch, J.M., Connors, K.A., Brooks, B.W. and Rand, G.M. 2012. Human pharmaceuticals in the aquatic environment: a review of recent toxicological studies and considerations for toxicity testing. Rev. Environ. Contam. Toxicol., 218: 1-99.

Dann, A.B. and Hontela, A. 2011. Triclosan: environmental exposure, toxicity, and mechanisms of action. J. Appl. Toxicol., 31: 285-311.

Daughton, C.G. and Ruhoy, I.S. 2013. Lower-dose prescribing: minimizing "side effects" of pharmaceuticals on society and the environment. Sci. Total Environ., 443: 324-337.

De Liguoro, M., Di Leva, V., Dalla Bona, M., Merlanti, R., Caporale, G. and Radaelli, G. 2012. Sublethal effects of trimethoprim on four freshwater organisms. Ecotoxicol. Environ. Saf., 82: 114-121.

De Vasconcelos, E., Dalke, C. and De Oliveira, C. 2017. Influence of select antibiotics on Vibrio fischeri and Desmodesmus subspicatus at $\mu \mathrm{g} \mathrm{L}-1$ concentration. Environ. Manag., 60: 157-164.

Deng, W., Li, N., Zheng, H. and Lin, H. 2016. Occurrence and risk assessment of antibiotics in river water in Hong Kong. Ecotoxicol. Environ. Saf., 125: 121-127.

Dong, D., Zhang, L., Liu, S., Guo, Z. and Hua, X. 2016. Antibiotics in water and sediments from Liao River in Jilin Province, China: occurrence, distribution, and risk assessment. Environ. Earth Sci., 75: 1202.

Ebert, I., Bachmann, J., Kühnen, U., Küster, A., Kussatz, C. and Maletzki, D. 2011. Toxicity of the fluoroquinolone antibiotics enrofloxacin and ciprofloxacin to photoautotrophic aquatic organisms. Environ. Toxicol. Chem., 30: 2786-2792.

Eguchi, K., Nagase, H., Ozawa, M., Endoh, Y.S., Goto, K. and Hirata, K. 2004. Evaluation of antimicrobial agents for veterinary use in the ecotoxicity test using microalgae. Chemosphere, 57: 1733-1738.

EMA E 2006. Guideline on the environmental risk assessment of medicinal products for human use. EMEA/CHMP/SWP/4447/00 Committee for Medicinal Products for Human Use (CHMP), London, UK.

Fairbairn, D.J., Karpuzcu, M.E., Arnold, W.A., Barber, B.L., Kaufenberg, E.F. and Koskinen, W.C. 2016. Sources and transport of contaminants of emerging concern: A two-year study of the occurrence and spatiotemporal variation in a mixed land-use watershed. Sci. Tot. Environ., 551: 605-613.

Faust, M., Altenburger, R., Backhaus, T., Blanck, H., Boedeker, W. and Gramatica, P. 2003. Joint algal toxicity of 16 dissimilarly acting chemicals is predictable by the concept of independent action. Aquat. Toxicol., 63: 43-63.

Gao, L., Shi, L. and Yuan, T. 2013. Growth inhibitive effect of typical antibiotics and their mixtures on Selenastrum capricornutum. J. Environ. Public Health, 30: 475-478.

González-Pleiter, M., Gonzalo, S., Rodea-Palomares, I., Leganés, F., Rosal, R. and Boltes, K. 2013. Toxicity of five antibiotics and their mixtures towards photosynthetic aquatic organisms: implications for environmental risk assessment. Water Res., 47: 2050-2064.

González-Pleiter, M., Cirés, S., Hurtado-Gallego, J., Leganés, F., FernándezPiñas, F. and Velázquez, D. 2013. Ecotoxicological assessment of antibiotics in freshwater using cyanobacteria. Cyanobacteria, 6(3): 399-417.

Gothwal, R. and Shashidhar, T. 2015. Antibiotic pollution in the environment: A review. Clean Soil Air Water, 43: 479-489.

Hagel, S. and Scheuerlein, H.J.V.M. 2014. Perioperative antibiotic prophylaxis and antimicrobial therapy of intra-abdominal infections. Viszeralmedizin, 30: 310-316.

Han, Q., Zheng, Y., Qi, Q., Peng, J., Song, J. and Guo, J. 2020. Involvement of oxidative stress in the sensitivity of two algal species exposed to roxithromycin. Ecotoxicology, 7: 1-9.

Hua, X., Zhao, Z., Zhang, L., Dong, D. and Guo, Z. 2018. Role of dissolved organic matter from natural biofilms in oxytetracycline photodegradation. Environ. Sci. \& Pollut. Res., 25: 30271-30280.

Huang, D.J., Hou, J.H., Kuo, T.F. and Lai, H.T. 2014. Toxicity of the veterinary sulfonamide antibiotic sulfamonomethoxine to five aquatic organisms. Pharmacology, 38: 874-880.

Isidori, M., Lavorgna, M., Nardelli, A., Pascarella, L. and Parrella, A. 2005. Toxic and genotoxic evaluation of six antibiotics on non-target organisms. Sci. Total Environ., 346: 87-98.

Johnson, A.C., Keller, V., Dumont, E. and Sumpter, J.P. 2015. Assessing the concentrations and risks of toxicity from the antibiotics ciprofloxacin, sulfamethoxazole, trimethoprim, and erythromycin in European rivers. Sci. Total Environ., 511: 747-755.

Kiki, C., Rashid, A., Wang, Y., Li, Y., Zeng, Q. and Yu, C.P. 2020. Dissipation of antibiotics by microalgae: Kinetics, identification of transformation products and pathways. J. Hazard. Mater., 387: 121985.

Kolar, B., Arnuš, L., Jeretin, B., Gutmaher, A., Drobne, D. and Durjava, M.K. 2014. The toxic effect of oxytetracycline and trimethoprim in the aquatic environment. Chemosphere, 115: 75-80.

Larsson, D.J. 2014. Antibiotics in the environment. Ups. J. Med. Sci., 119: $108-112$.

Laxminarayan, R., Duse, A., Wattal, C., Zaidi, A.K., Wertheim, H.F. and Sumpradit, N. 2013. Antibiotic resistance-the need for global solutions. Lancet Infect. Dis., 13: 1057-1098. 
Laxminarayan, R., Matsoso, P., Pant, S., Brower, C., Røttingen, J.A. and Klugman, K. 2016. Access to effective antimicrobials: a worldwide challenge. The Lancet, 387: 168-175.

Li, J., Min, Z., Li, W., Xu, L., Han, J. and Li, P. 2020. Interactive effects of roxithromycin and freshwater microalgae, Chlorella pyrenoidosa: Toxicity and removal mechanism. Ecotoxicol. Environ. Saf., 191: 110156.

Li, Y., Zhang, B., He, X., Cheng, W.H., Xu, W. and Luo, Y. 2014. Analysis of individual and combined effects of ochratoxin A and zearalenone on HepG2 and KK-1 cells with mathematical models. Toxins 6: 1177-1192.

Liang, X., Chen, B., Nie, X., Shi, Z., Huang, X. and Li, X. 2013. The distribution and partitioning of common antibiotics in water and sediment of the Pearl River Estuary, South China. Chemosphere, 92: 1410-1416.

Liu, B.Y., Nie, X.P., Liu, W.Q., Snoeijs, P., Guan, C. and Tsui, M.T. 2011. Toxic effects of erythromycin, ciprofloxacin, and sulfamethoxazole on photosynthetic apparatus in Selenastrum capricornutum. Ecotoxicol. Environ. Saf., 74: 1027-1035.

Liu, L., Wu, W., Zhang, J., Lv, P., Xu, L. and Yan, Y. 2018. Progress of research on the toxicology of antibiotic pollution in aquatic organisms. Acta Ecol. Sin., 38: 36-41.

Liu, Y., Wang, Y., Zhang, J., Sun, L., Zhang, A. and Torres, O.L. 2017. An integrated assessment of ceftazidime and photo products on the feeding behavior of rotifers: From exposure to post-exposure. Ecotoxicol. Environ. Saf., 144: 245-251.

Machado, M.M.D. and Soares, E.V. 2018. Toxic effects of erythromycin to freshwater and marine microalgae. Environ. Pollut., 242: 357-366.

Magdaleno, A., Saenz, M., Juárez, A. and Moretton, J. 2015. Effects of six antibiotics and their binary mixtures on the growth of Pseudokirchneriella subcapitata. Ecotoxicol. Environ. Saf., 113: 72-78.

Manzetti, S. and Ghisi, R. 2014. The environmental release and fate of antibiotics. Mar. Pollut. Bull., 79: 7-15.

Martins, N., Pereira, R., Abrantes, N., Pereir,a J., Gonçalves, F. and Marques, C. 2012. Ecotoxicological effects of ciprofloxacin on freshwater species: data integration and derivation of toxicity thresholds for risk assessment. Ecotoxicology, 21: 1167-1176.

Matsumoto, H., Takechi, K., Sato, H., Takio, S. and Takano, H. 2012. Treatment with antibiotics that interfere with peptidoglycan biosynthesis inhibits chloroplast division in the desmid Closterium. PLoS One, 7: 23-38.

Mazel, D. and Davies, J. 1999. Antibiotic resistance in microbes. Cell. Mol. Life Sci., 56: 742-754.

Minguez, L., Pedelucq, J., Farcy, E., Ballandonne, C., Budzinski, H. and Halm-Lemeille, M.P. 2016. Toxicities of 48 pharmaceuticals and their freshwater and marine environmental assessment in northwestern France. Environ. Sci. \& Pollut. Res., 23: 4992-5001.

Mitchell, S.M., Ullman, J.L., Teel, A.L. and Watts, R.J. 2014. pH and temperature effects on the hydrolysis of three D-lactam antibiotics: Ampicillin, cefalotin, and cefoxitin. Sci. Total Environ., 466: 547-555.

Moullan, N., Mouchiroud, L., Wang, X., Ryu, D., Williams, E.G. and Mottis, A. 2015. Tetracyclines disturb mitochondrial function across eukaryotic models: a call for caution in biomedical research. Cell Rep., 10: $1681-1691$.

Mutiyar, P.K. and Mittal, A.K. 2014. Occurrences and fate of selected human antibiotics in influents and effluents of the sewage treatment plant and effluent-receiving river Yamuna in Delhi (India). Environ. Monit. Assess., 186: 541-557.

Ngumba, E., Gachanja, A. and Tuhkanen, T. 2016. Occurrence of selected antibiotics and antiretroviral drugs in Nairobi River Basin, Kenya. Sci. Total Environ., 539: 206-213.

Niu, Z., Na, J., Lv, Z. and Zhang, Y. 2019. How long-term exposure of environmentally relevant antibiotics may stimulate the growth of Prorocentrum lima: A probable positive factor for red tides. Environ. Pollut., 255: 113149.
Noguera-Oviedo, K. and Aga, D.S. 2016. Lessons learned from more than two decades of research on emerging contaminants in the environment. J. Hazard. Mater., 316: 242-251.

Nweke, C., Orji, J. and Ahumibe, N. 2015. Prediction of phenolic compound and formulated glyphosate toxicity in binary mixtures using Rhizobium species dehydrogenase activity. Adv. Life Sci., 5: 27-38.

Pal, A., He, Y., Jekel, M., Reinhard, M. and Gin K.Y.H. (2014). Emerging contaminants of public health significance as water quality indicator compounds in the urban water cycle. environ.Int., 71: 46-62.

Robinson, A.A., Belden, J.B. and Lydy, M.J. 2005. Toxicity of fluoroquinolone antibiotics to aquatic organisms. Int.J. Environ. Toxicol. Chem., 24: 423-430.

Roose-Amsaleg, C. and Laverman, A.M. 2016. Do antibiotics have environmental side effects? Impact of synthetic antibiotics on biogeochemical processes. Environ. Pollut. Sci. Res., 23: 4000-4012.

Sebaugh, J. 2011. Guidelines for accurate EC50/IC50 estimation. Pharm. Stat., 10: 128-134.

Seoane, M., Rioboo, C., Herrero, C. and Cid, A. 2014. Toxicity induced by three antibiotics commonly used in aquaculture on the marine microalga Tetraselmis suecica (Kylin) Butch. Mar. Environ. Res., 101: 1-7.

Shade, A., Klimowicz, A.K., Spear, R.N., Linske, M., Donato, J.J. and Hogan, C.S. 2013. Streptomycin application has no detectable effect on bacterial community structure in apple orchard soil. Appl. Environ. Microbiol., 79: 6617-6625.

Siedlewicz, G., Żak, A., Sharma, L., Kosakowska, A. and Pazdro, K. 2020. Effects of oxytetracycline on growth and chlorophyll a fluorescence in green algae (C. vulgaris), diatom (Phaeodactylum tricornutum), and cyanobacteria (Microcystis aeruginosa and Nodularia spumigena). Oceanologia, 31: 411-431.

Singh, S.K., Sengupta, S., Antony, R., Bhattacharya, S., Mukhopadhyay, C. and Ramasubramanian, V. 2019. Variations in antibiotic use across India-Multicentre study through global point prevalence survey. J. Hosp. Infect., 3: 54

Smith, T.C., Gebreyes, W.A., Abley, M.J., Harper, A.L., Forshey, B.M. and Male, M.J. 2013. Methicillin-resistant Staphylococcus aureus in pigs and farm workers on conventional and antibiotic-free swine farms in the USA. Plos One, 8: e63704.

Song, C., Wei, Y., Qiu, Y., Qi, Y., Li, Y. and Kitamura, Y. 2019. Biodegradability and mechanism of florfenicol via Chlorella sp. UTEX1602 and L38: Experimental study. Bioresour. Technol., 272: 529-534.

Tian, Y., Zou, J., Feng, L., Zhang, L. and Liu Y 2019. C. vulgaris enhance the photodegradation of chlortetracycline in aqueous solution via extracellular organic matters (EOMs): Role of triplet state EOMs. Water Res., 149: 35-41.

Välitalo, P., Kruglova, A., Mikola, A. and Vahala, R. 2017. Toxicological impacts of antibiotics on aquatic micro-organisms: a mini-review. Int. J. Hyg. Environ. Health, 220: 558-569.

Van Boeckel, T.P., Gandra, S., Ashok, A., Caudron, Q., Grenfell, B.T. and Levin, S.A. 2014. Global antibiotic consumption 2000 to 2010: An analysis of national pharmaceutical sales data. Lancet Infect. Dis., 14: 742-750.

Van Boeckel, T.P., Brower, C., Gilbert, M., Grenfell, B.T., Levin, S.A. and Robinson, T.P. 2015. Global trends in antimicrobial use in food animals. Proc. Natl. Acad. Sci., 112: 5649-5654.

Villain, J., Minguez, L., Halm-Lemeille, M.P., Durrieu, G. and Bureau, R. 2016. Acute toxicities of pharmaceuticals toward green algae. mode of action, biopharmaceutical drug disposition classification system, and quantile regression models. Ecotoxicol. Environ. Saf., 124: 337-343.

Vilvert, E., Contardo-Jara, V., Esterhuizen-Londt, M. and Pflugmacher, S. 2017. The effect of oxytetracycline on physiological and enzymatic defense responses in aquatic plant species Egeria densa, Azolla caroliniana, and Taxiphyllum barbieri. Toxicol. Environ. Chem., 99: 104-116. 
Wan, J., Guo, P. and Zhang, S. 2014. Response of the cyanobacterium Microcystis flos-aquae to levofloxacin. Environ. Sci. \& Pollut. Rese., 21: 3858-3865.

Wang, G., Zhang, Q., Li, J., Chen, X., Lang, Q. and Kuang, S. 2019. Combined effects of erythromycin and enrofloxacin on antioxidant enzymes and photosynthesis-related gene transcription in C. vulgaris. Aquat. Toxicol., 212: 138-145.

Wang, X., Ryu, D., Houtkooper, R.H. and Auwerx, J. 2015. Antibiotic use and abuse: a threat to mitochondria and chloroplasts with impact on research, health, and environment. Bioessays, 37: 1045-1053.

Wang, X., Zheng, Y., Zhang, Y., Li, J., Zhang, H. and Wang, H.J.C. 2016. Effects of Q-diketone antibiotic mixtures on the behavior of zebrafish (Danio rerio). Europe PMC, 144: 2195-2205.

Wei R, Ge F, Huang S, Chen M, Wang R (2011). Occurrence of veterinary antibiotics in animal wastewater and surface water around farms in Jiangsu Province, China. Chemosphere 82: 1408-1414.

Wei R, Ge F, Chen M, Wang R (2012). Occurrence of ciprofloxacin, enrofloxacin, and florfenicol in animal wastewater and water resources. Journal of environmental quality 41: 1481-1486.

Wu, M.H., Que, C.J., Xu, G., Sun, Y.F., Ma, J. and Xu, H. 2016a. Occurrence, fate, and interrelation of selected antibiotics in sewage treatment plants and their receiving surface water. Ecotoxicol. Environ. Saf., 132: 132-139.

Wu, M.H., Que, C., Tang, L., Xu, H., Xiang, J. and Wang, J. 2016 b. Distribution, fate, and risk assessment of antibiotics in five wastewater treatment plants in Shanghai, China. Environ. Sci. Pollut. Res., 23: 18055-18063.

Xiang, L., Wu, X.L., Jiang, Y.N., Yan, Q.Y., Li, Y.W. and Huang, X.P.
2016. Occurrence and risk assessment of tetracycline antibiotics in soil from organic vegetable farms in a subtropical city, south China. Environ. Sci. Pollut. Res. Int., 23: 13984-13995.

Yan, C., Yang, Y., Zhou, J., Liu, M., Nie, M. and Shi, H. 2013. Antibiotics in the surface water of the Yangtze Estuary: occurrence, distribution and risk assessment. Environ. Pollut., 175: 22-29.

Yang, L.H., Ying, G.G., Su, H.C., Stauber, J.L., Adams, M.S. and Binet, M.T. 2008. Growth-inhibiting effects of 12 antibacterial agents and their mixtures on the freshwater microalga pseudokirchneriella subcapitata. Int. J. Environ. Toxicol. Chem., 27: 1201-1208.

Yang, W., Tang, Z., Zhou, F., Zhang, W. and Song, L. 2013. Toxicity studies of tetracycline on Microcystis aeruginosa and Selenastrum capricornutum. Environ. Toxicol. Pharmacol., 35: 320-324.

Yang, Y., Li, B., Zou, S., Fang, H.H. and Zhang, T. 2014. The fate of antibiotic resistance genes in sewage treatment plants revealed by a metagenomic approach. Water Res., 62: 97-106.

Zhang, G., Liu, X., Lu, S., Zhang, J. and Wang, W. 2020. Occurrence of typical antibiotics in Nansi Lake's inflowing rivers and antibiotic source contribution to Nansi Lake based on principal component analysis-multiple linear regression model. Chemosphere, 242: 125269.

Zhou, Z., Zhang, Z., Feng, L., Zhang, J., Li, Y. and Lu, T. 2020. Adverse effects of levofloxacin and oxytetracycline on aquatic microbial communities. Sci. Total Environ., 13(9): 499.

Zorpas, A.A., Dimitriou, M. and Voukkali, I. 2018. Disposal of household pharmaceuticals in insular communities: Social attitude, behavior evaluation, and prevention activities. Environ. Sci. \& Pollut., 25: 26725-26735. 